Industries Ltd, and Valeant Pharmaceuticals, Grant/research support from: AbbVie, Amgen, Arcutis Biotherapeutics, Boehringer Ingelheim, Bristol Myers Squibb, Celgene Corporation, Corrona, LLC, Dermavant Sciences, LTD, Dermira/UCB, Eli Lilly and Company, Glenmark Pharmaceuticals Ltd, Janssen Biotech, Kadmon Corporation, Leo Pharma, Lycera Corp, Menlo Therapeutics, Novartis, Pfizer, Regeneron Pharmaceuticals, Sun Pharma, Taro Pharmaceutical Industries Ltd, and Valeant Pharmaceuticals, Mark Lebwohl Consultant of: Aditum Bio, Allergan, Almirall, Arcutis, Inc., Avotres Therapeutics, BirchBioMed Inc., BMD skincare, Boehringer-Ingelheim, Bristol-Myers Squibb, Cara Therapeutics, Castle Biosciences, Corrona, Dermavant Sciences, Evelo, Evommune, Facilitate International Dermatologic Education, Foundation for Research and Education in Dermatology, Inozyme Pharma, Kyowa Kirin, LEO Pharma, Meiji Seika Pharma, Menlo, Mitsubishi, Neuroderm, Pfizer, Promius/Dr. Reddy's Laboratories, Serono, Theravance, and Verrica, Grant/ research support from: Abbvie, Amgen, Arcutis, Boehringer Ingelheim, Dermavant, Eli Lilly, Evommune, Incyte, Janssen, Leo Pharmaceutucals, Ortho Dermatologics, Pfizer, and UCB, Ya-Wen Yang Shareholder of: Johnson \& Johnson, Employee of: Janssen Global Services, LLC, May Shawi Shareholder of: Johnson \& Johnson, Employee of: Janssen Global Services, LLC, Megan Miller Shareholder of: Johnson \& Johnson, Employee of: Janssen Research \& Development, LLC, Alexa Kollmeier Shareholder of: Johnson \& Johnson, Employee of: Janssen Research \& Development, LLC, Elizabeth C Hsia Shareholder of: Johnson \& Johnson, Employee of: Janssen Research \& Development, LLC, Xie L Xu Shareholder of: Johnson \& Johnson, Employee of: Janssen Research \& Development, LLC, Miwa Izutsu Shareholder of: Johnson \& Johnson, Employee of: Janssen Research \& Development, LLC, Paraneedharan Ramachandran Shareholder of: Johnson \& Johnson, Employee of: Janssen Research \& Development, LLC, Shihong Sheng Shareholder of: Johnson \& Johnson, Employee of: Janssen Research \& Development, LLC, Yin You Shareholder of: Johnson \& Johnson, Employee of: Janssen Research \& Development, LLC, Philip Helliwell Consultant of: Galapagos, Janssen, Novartis, Grant/research support from: Abbvie, Janssen, Pfizer, Wolf-Henning Boehncke Speakers bureau: AbbVie, Almirall, Celgene, Janssen, Leo, Lilly, Novartis, and UCB Pharma, Consultant of: AbbVie, Almirall, Celgene, Janssen, Leo, Lilly, Novartis, and UCB Pharma, Grant/research support from: Pfizer

DOI: 10.1136/annrheumdis-2021-eular.558

\begin{tabular}{|l|l|}
\hline POS1032 & EFFICACY OF UPADACITINIB IN PATIENTS WITH \\
& PSORIATIC ARTHRITIS STRATIFIED BY NUMBER \\
& OF PRIOR BIOLOGIC DISEASE-MODIFYING ANTI- \\
& RHEUMATIC DRUGS
\end{tabular}

P. J. Mease ${ }^{1}$, A. Lertratanakul $\left.\right|^{2}$, B. Strober ${ }^{3}$, S. Tsuji ${ }^{4}$, P. Richette ${ }^{5}$, C. Lovan ${ }^{2}$ D. Feng ${ }^{2}$, J. Anderson ${ }^{2}$, F. Van den Bosch ${ }^{6} .{ }^{1}$ Department of Rheumatology, Swedish Medical Center and University of Washington, Seattle, United States of America; ${ }^{2}$ AbbVie Inc., Rheumatology, North Chicago, United States of America; ${ }^{3}$ Yale University School of Medicine, New Haven and Central Connecticut Dermatology, Cromwell, United States of America; ${ }^{4}$ Department of Orthopaedics/ Rheumatology, National Hospital Organization, Osaka Minami Medical Center, Osaka, Japan; ${ }^{5}$ Department of Rheumatology, Lariboisière Hospital, Paris, France; ${ }^{6}$ Department of Internal Medicine, Ghent University Hospital, Ghent, Belgium

Background: Upadacitinib (UPA) has shown efficacy and safety in patients (pts) with active PsA in the Phase 3 SELECT-PsA 1 and SELECT-PsA 2 clinical trials. ${ }^{1,2}$ Historically efficacy has been lower with second- and third-line therapy compared with first-line anti-TNF therapy in PsA; ${ }^{3,4}$ however, clinical trial data that describe efficacy in pts who have had an inadequate response (IR) to multiple biologic DMARDs (bDMARDs) are limited.

Objectives: This analysis assessed the effects of prior bDMARD failure on UPA efficacy in the SELECT-PSA 2 trial.

Methods: The SELECT-PsA 2 study enrolled pts with prior IR or intolerance to $\geq 1$ bDMARD ( $N=642$ ). Pts were randomized to placebo (PBO), UPA $15 \mathrm{mg}$ once daily (QD, UPA15), or UPA $30 \mathrm{mg}$ QD (UPA30). Stable background treatment of $\leq 2$ non-bDMARDs was permitted; background therapy was not required. Only the pts who had IR to $\geq 1$ bDMARD were included in this analysis; pts were subgrouped based on the number of bDMARDs failed prior to enrollment $(1,2$, or $\geq 3)$. This analysis includes assessment of proportion of pts achieving ACR20/50/70, and change in HAQ-DI, FACIT-Fatigue, and SF-36 Physical Component Summary at Wk 12; static Investigator Global Assessment of Psoriasis of 0 or 1 and at least a 2-point improvement from baseline, PASI75, and change in Self-Assessment of Psoriasis Symptoms at Wk 16; and proportion of pts achieving minimal disease activity (MDA) at Wk 24. Non-responder imputation was used for binary endpoints. Mixed-effects model for repeated measures was used for continuous endpoints. Point estimates and $95 \%$ confidence intervals (Cls) of the PBO subtracted treatment effect were calculated.

Results: 641 pts were randomized and received study drug; 92\% were bDMARD-IR: $391(61 \%)$ of pts failed 1 bDMARD, $116(18 \%)$ failed 2 bDMARDs, and $83(13 \%)$ failed $\geq 3$ bDMARDs. In the overall study population, UPA15 and UPA30 demonstrated superiority vs placebo for all endpoints evaluated. In this post hoc analysis, the PBO subtracted treatment effect demonstrates generally consistent efficacy as compared to the overall study population for UPA15 and UPA30 across efficacy endpoints in the subgroups of pts with IR to 1,2 , or $\geq 3$ prior bDMARDs (Figure 1). Due to limited sample sizes for pts with IR to $>1$ bDMARD and the pt subsets analyzed for psoriasis-related endpoints, results should be interpreted with caution.
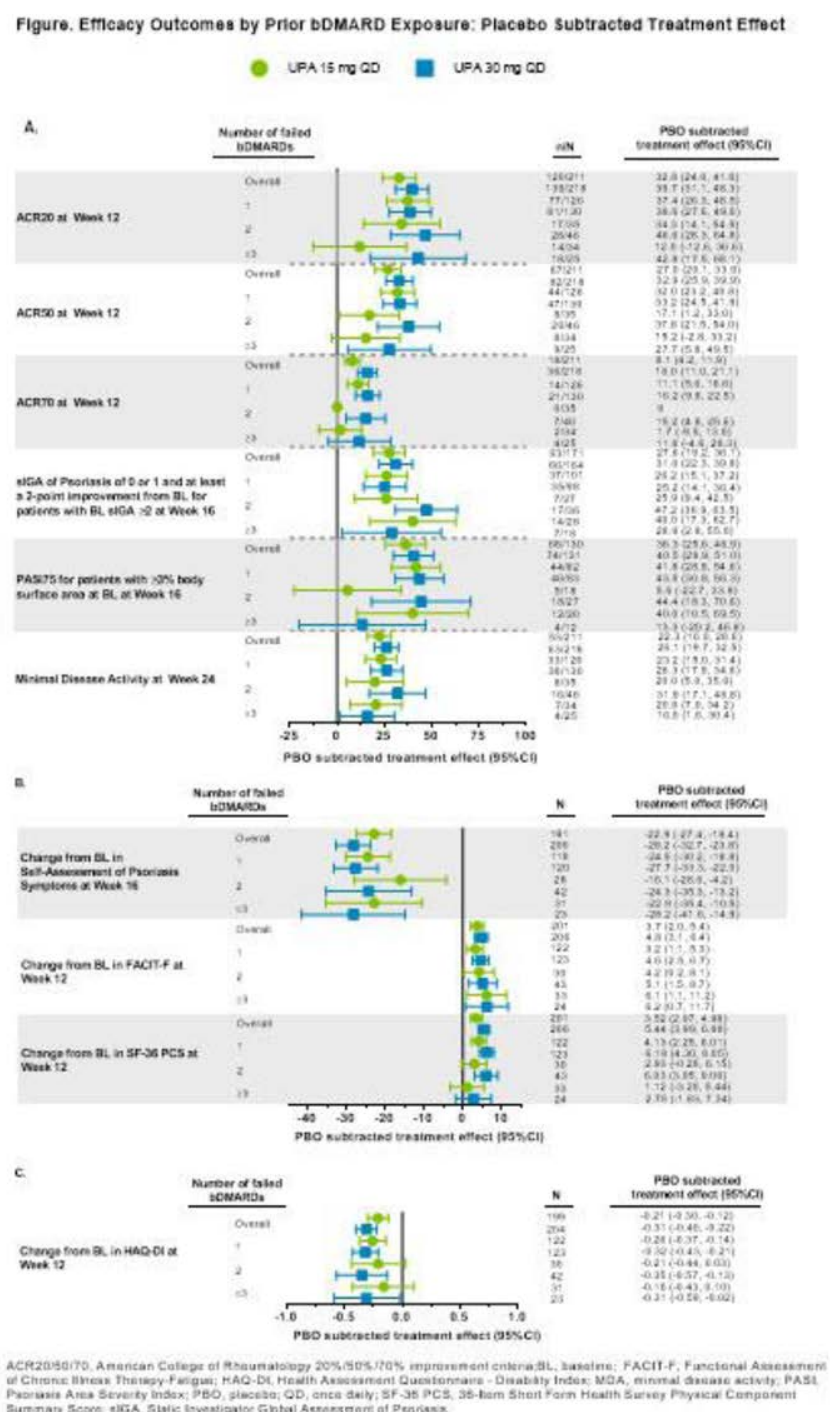

Conclusion: Upadacitinib demonstrated consistent efficacy in treating clinical manifestations of PsA including musculoskeletal symptoms, psoriasis, physical function, fatigue, and quality of life in pts with IR to 1 or multiple prior bDMARDs. In addition, comprehensive disease control as measured by MDA, was generally consistently achieved with upadacitinib regardless of number of prior bDMARDs tried. REFERENCES:

[1] McInnes IB, et al. Ann Rheum Dis, 2020; 79:12.

[2] Genovese MC, et al. Ann Rheum Dis, 2020; 79:139.

[3] Costa L, et al. Drugs R D. 2017;17:509-522.

[4] Reddy SM, et al. 2016;35:2955-2966.

Acknowledgements: AbbVie and the authors thank the patients, study sites, and investigators who participated in this clinical trial. AbbVie, Inc was the study sponsor, contributed to study design, data collection, analysis \& interpretation, and to writing, reviewing, and approval of final version. No honoraria or payments were made for authorship. Medical writing support was provided by Ramona Vladea, PhD of AbbVie Inc.

Disclosure of Interests: Philip J Mease Speakers bureau: AbbVie, Amgen, Boehringer Ingelheim, Bristol Myers, Celgene, Galapagos, Genentech, Gilead, GlaxosmithKline, Janssen, Lilly, Merck, Novartis, Pfizer, Sun Pharma, and UCB. Consultant of: AbbVie, Amgen, Boehringer Ingelheim, Bristol Myers, Celgene, Galapagos, Genentech, Gilead, GlaxosmithKline, Janssen, Lilly, Merck, Novartis, Pfizer, Sun Pharma, and UCB., Grant/research support from: AbbVie, Amgen, Boehringer Ingelheim, Bristol Myers, Celgene, Galapagos, Genentech, Gilead, GlaxosmithKline, Janssen, Lilly, Merck, Novartis, Pfizer, Sun Pharma, and UCB., Apinya Lertratanaku Shareholder of: AbbVie, Employee of: AbbVie, Bruce Strober Speakers bureau: AbbVie, Amgen, Eli Lilly, Janssen, Ortho Dermatologics, Consultant of: AbbVie, Almirall, 
Amgen, Arcutis, Arena, Aristea, Boehringer Ingelheim, Bristol-Myers-Squibb, Cara, Celgene, Dermavant, Dermira, Janssen, Leo, Eli Lilly, Meiji Seika Pharma, Novartis, Pfizer, GlaxoSmithKline, UCB Pharma, Sun Pharma, Ortho Dermatologics, Regeneron, Sanofi-Genzyme, Shigeyoshi Tsuji Speakers bureau: AbbVie Inc., Celgene, Eli Lilly, Janssen, Merck, Novartis, Pfizer and UCB, Consultant of: AbbVie Inc., Celgene, Eli Lilly, Janssen, Merck, Novartis, Pfizer and UCB, Pascal Richette Speakers bureau: AbbVie, Biogen, Janssen, BMS, Roche, Pfizer, Amgen, Sanofi-Aventis, UCB, Lilly, Novartis, and Celgene, Consultant of: AbbVie, Biogen, Janssen, BMS, Roche, Pfizer, Amgen, Sanofi-Aventis, UCB, Lilly, Novartis, and Celgene, Charles Lovan Shareholder of: AbbVie, Employee of: AbbVie, Dai Feng Shareholder of: AbbVie, Employee of: AbbVie, Jaclyn Anderson Shareholder of: AbbVie, Employee of: AbbVie, Filip van den Bosch Speakers bureau: AbbVie Inc., Celgene, Eli Lilly, Janssen, Merck, Novartis, Pfizer and UCB, Consultant of: AbbVie Inc., Celgene, Eli Lilly, Janssen, Merck, Novartis, Pfizer and UCB.

DOI: 10.1136/annrheumdis-2021-eular.564

\section{POS1033 SAFETY OF IXEKIZUMAB IN PATIENTS WITH PSORIATIC ARTHRITIS: AN INTEGRATED ANALYSIS OF 4 CLINICAL TRIALS}

C. Sesin ${ }^{1}$, G. Gallo², A. Gellett' ${ }^{2}$ A. Kronbergs ${ }^{2}$, A. T. Sprabery ${ }^{2}$, W. $\mathrm{Xu}^{2}$, H. Patel ${ }^{2}$, A. Deodhar ${ }^{3}$, B. Combe ${ }^{4}$, G. R. Burmester ${ }^{5} .{ }^{1}$ Mount Sinai Medical Center, Miami Beach, United States of America; ${ }^{2}$ Eli Lilly and Company, Indianapolis, United States of America; ${ }^{3}$ Oregon Health \& Science University, Portland, United States of America; ${ }^{4}$ Montpellier University, CHU Montpellier, Montpellier, France; ${ }^{5}$ Universitatsklinikum Charite, Berlin, Germany

Background: Patients with psoriatic arthritis (PsA) require long-term treatment, which may lead to adverse events (AEs). Ixekizumab, an interleukin-17A antagonist, is approved for the treatment of adults with active PsA.

Objectives: We report a summary of safety outcomes for patients enrolled in 4 PsA studies with up to 3 years of exposure to ixekizumab.

Methods: This integrated safety analysis included all patients with PsA who received at least 1 dose of ixekizumab ( $80 \mathrm{mg}$ every 2 or 4 weeks) in 4 clinical trials (NCT01695239, NCT02349295, NCT02584855, NCT03151551). Safety outcomes included treatment-emergent adverse events (TEAEs), serious AEs (SAEs), discontinuations due to AEs, deaths, and AEs of special interest.

Results: A total of 1401 patients were included in this safety analysis (51.5\% female; mean age 49 years), with 2247.6 patient-years of exposure (Table 1). In all, 1131 patients $(80.7 \%$ ) reported $\geq 1$ TEAE (exposure-adjusted incidence rate per 100 patient-years [IR] $50.3,95 \% \mathrm{Cl} 47.5-53.3)$, mostly mild (32.9\%) or moderate $(39.7 \%)$ in severity. The most common TEAEs were nasopharyngitis ( $n=202$, IR 9.0), upper respiratory infections $(n=186$, IR 8.3$)$, and injection site reaction $(n=156$, IR 6.9$)$. SAEs were reported by 134 patients (IR $6.0,95 \% \mathrm{CI}$ $5.0-7.1$ ). 115 (8.2\%) patients discontinued due to AEs (IR 5.1, 95\% Cl 4.3-6.1). Six deaths were reported (IR $0.3,95 \% \mathrm{Cl} 0.1-0.6$ ). Allergic reactions/hypersensitivity were reported in 102 patients (IR 4.5, 95\% Cl 3.7-5.5). Three cases were adjudicated as de novo inflammatory bowel disease (IR $0.13,95 \% \mathrm{Cl} 0.04-0.41$ ); 1 was ulcerative colitis (IR $0.04,95 \% \mathrm{Cl} 0.01-0.32$ ), 2 were Crohn's disease (IR

Pooled Ixekizumab

( $N=1401$; Total Patient-Years=2247.6)

\begin{tabular}{|c|c|c|c|c|c|}
\hline & $\begin{array}{c}n(I R) \\
95 \% \mathrm{Cl}\end{array}$ & $\begin{array}{c}\begin{array}{c}\text { Year 0-1 } \\
(\mathrm{n}=1401) \\
\mathrm{n}(\mathrm{IR})\end{array} \\
95 \% \mathrm{Cl}\end{array}$ & $\begin{array}{c}\text { Year 1-2 } \\
(\mathrm{n}=946) \\
\mathrm{n}(\mathrm{IR}) \\
95 \% \mathrm{Cl}\end{array}$ & $\begin{array}{c}\text { Year 2-3 } \\
(n=510) \\
n(I R) \\
95 \% \mathrm{Cl}\end{array}$ & $\begin{array}{c}\text { Year } \geq 3 \\
(n=89) \\
n(I R) \\
95 \% \mathrm{Cl}\end{array}$ \\
\hline Total Patient-Years & 2247.7 & 1207.3 & 689.8 & 347.7 & 2.9 \\
\hline Patients with $\geq 1$ TEAE & $\begin{array}{c}1131(50.3) \\
47.5-53.3\end{array}$ & $\begin{array}{c}1050(87.0) \\
81.9-92.4\end{array}$ & $\begin{array}{l}496(71.9) \\
65.9-78.5\end{array}$ & $\begin{array}{l}234(67.3) \\
59.2-76.5\end{array}$ & $\begin{array}{c}6(206.2) \\
92.6-458.9\end{array}$ \\
\hline SAES & $\begin{array}{c}134(6.0) \\
5.0-7.1\end{array}$ & $\begin{array}{c}72(6.0) \\
4.7-7.5\end{array}$ & $\begin{array}{c}53(7.7) \\
5.9-10.1\end{array}$ & $\begin{array}{l}19(5.5) \\
3.5-8.6\end{array}$ & $\begin{array}{c}1(34.4) \\
4.8-243.9\end{array}$ \\
\hline Discontinuations due to AEs & $\begin{array}{c}115(5.1) \\
4.3-6.1\end{array}$ & $\begin{array}{l}61(5.1) \\
3.9-6.5\end{array}$ & $\begin{array}{l}37(5.4) \\
3.9-7.4\end{array}$ & $\begin{array}{l}17(4.9) \\
3.0-7.9\end{array}$ & $\begin{array}{c}0(0) \\
0.0-274.7\end{array}$ \\
\hline Hepatic reactions & $\begin{array}{c}112(5.0) \\
4.1-6.0\end{array}$ & $\begin{array}{l}80(6.6) \\
5.3-8.3\end{array}$ & $\begin{array}{l}32(4.6) \\
3.3-6.6\end{array}$ & $\begin{array}{l}14(4.0) \\
2.4-6.8\end{array}$ & $\begin{array}{c}0(0) \\
0.0-274.7\end{array}$ \\
\hline Allergic reaction/hypersensitivity & $\begin{array}{c}102(4.5) \\
3.7-5.5\end{array}$ & $\begin{array}{l}83(6.9) \\
5.5-8.5\end{array}$ & $\begin{array}{l}23(3.3) \\
2.2-5.0\end{array}$ & $\begin{array}{c}5(1.4) \\
0.6-3.5\end{array}$ & $\begin{array}{c}0(0) \\
0.0-274.7\end{array}$ \\
\hline Serious infection & $\begin{array}{l}28(1.2) \\
0.9-1.8\end{array}$ & $\begin{array}{l}18(1.5) \\
0.9-2.4\end{array}$ & $\begin{array}{c}9(1.3) \\
0.7-2.5\end{array}$ & $\begin{array}{l}3(0.9) \\
0.3-2.7\end{array}$ & $\begin{array}{c}0(0) \\
0.0-274.7\end{array}$ \\
\hline Malignancies & $\begin{array}{l}15(0.7) \\
0.4-1.1\end{array}$ & $\begin{array}{c}4(0.3) \\
0.1-0.9\end{array}$ & $\begin{array}{c}8(1.2) \\
0.6-2.3\end{array}$ & $\begin{array}{c}4(1.2) \\
0.4-3.1\end{array}$ & $\begin{array}{c}0(0) \\
0.0-274.7\end{array}$ \\
\hline Major adverse cardiac events & $\begin{array}{l}12(0.5) \\
0.3-0.9\end{array}$ & $\begin{array}{c}3(0.2) \\
0.1-0.8\end{array}$ & $\begin{array}{c}8(1.2) \\
0.6-2.3\end{array}$ & $\begin{array}{l}1(0.3) \\
0.0-2.0\end{array}$ & $\begin{array}{c}0(0) \\
0.0-274.7\end{array}$ \\
\hline Inflammatory bowel disease & $\begin{array}{c}3(0.1) \\
0.0-0.4\end{array}$ & $\begin{array}{c}3(0.2) \\
0.1-0.8\end{array}$ & $\begin{array}{l}1(0.1) \\
0.0-1.0\end{array}$ & $\begin{array}{c}0(0.0) \\
0.0-2.3\end{array}$ & $\begin{array}{c}0(0.0) \\
0.0-274.7\end{array}$ \\
\hline Ulcerative colitis & $\begin{array}{c}1(0.0) \\
0.0-0.3\end{array}$ & $\begin{array}{l}1(0.1) \\
0.0-0.6\end{array}$ & $\begin{array}{l}1(0.1) \\
0.0-1.0\end{array}$ & $\begin{array}{c}0(0.0) \\
0.0-2.3\end{array}$ & $\begin{array}{c}\mathbf{0}(\mathbf{0 . 0}) \\
0.0-274.7\end{array}$ \\
\hline Crohn's disease & $\begin{array}{l}2(0.1) \\
0.0-0.4\end{array}$ & $\begin{array}{l}2(0.2) \\
0.0-0.7\end{array}$ & $\begin{array}{l}0(0.0) \\
0.0-1.2\end{array}$ & $\begin{array}{c}0(0.0) \\
0.0-2.3\end{array}$ & $\begin{array}{c}\mathbf{0}(\mathbf{0 . 0}) \\
0.0-274.7\end{array}$ \\
\hline
\end{tabular}

$\mathrm{AE}$, adverse event; $\mathrm{Cl}$, confidence interval; IR, exposure-adjusted incidence rate per 100 patient-years; SAE, serious adverse event; TEAE, treatment-emergent adverse event.
$0.09,95 \% \mathrm{Cl} 0.02-0.36)$. Major adverse cardiac events occurred in 12 patients (IR 0.5) and malignancies in 15 (IR 0.7), 9 of which were non-melanoma skin cancer. Opportunistic infections occurred in 40 (2.9\%) patients (IR 1.8, 95\% C 1.3-2.4). Candidiasis occurred in 24 patients (oral: IR $0.7,95 \% \mathrm{Cl} 0.4-1.2$; ora fungal infection: IR $0.3,95 \% \mathrm{Cl} 0.1-0.6$; esophageal infection: IR $0.1,95 \% \mathrm{C}$ $0.0-0.4)$. No active or reactive cases of tuberculosis were reported. Other opportunistic infections included hepatitis $\mathrm{B}$ (IR $0.0,95 \% \mathrm{Cl} 0.0-0.3)$, herpes simplex (IR 1.8, 95\% Cl 1.3-2.5), and herpes zoster (IR 0.7, 95\% Cl 0.4-1.2).

Conclusion: The safety profile of ixekizumab across 4 clinical trials and up to 3 years of continuous treatment in patients with active PSA was consistent with the known safety profile reported in previous studies for psoriasis and PsA. No new safety events were found in this analysis.

Disclosure of Interests: Carlos Sesin Speakers bureau: Amgen, AbbVie, Sanofi, Radius, Pfizer, Eli Lilly and Company, Novartis, Gaia Gallo Shareholder of: Eli Lilly and Company, Employee of: Eli Lilly and Company, Amanda Gellett Shareholder of: Eli Lilly and Company, Employee of: Eli Lilly and Company, Andris Kronbergs Shareholder of: Eli Lilly and Company, Employee of: Eli Lilly and Company, Aubrey Trevelin Sprabery Shareholder of: Eli Lilly and Company, Employee of: Eli Lilly and Company, Wen Xu Shareholder of: Eli Lilly and Company, Employee of: Eli Lilly and Company, Himanshu Patel Shareholder of: Eli Lilly and Company, Employee of: Eli Lilly and Company, Atul Deodhar Consultant of: AbbVie, Amgen, Boehringer Ingelheim, Bristol Myers Squibb, Celgene, Eli Lilly and Company, Galapagos, Glaxo Smith \& Kline, Janssen, Novartis, Pfizer, UCB, Grant/research support from: AbbVie, Eli Lilly and Company, Glaxo Smith \& Kline, Novartis, Pfizer, UCB, Bernard Combe Speakers bureau: AbbVie, BMS Gilead-Galapagos, Eli Lilly and Company, MSD, Pfizer, Roche Chugai, Consultant of: AbbVie, Bayer, Gilead-Galapagos, Janssen, Eli Lilly and Company, Novartis, Roche Chugai, Grant/research support from: AbbVie, Eli Lilly and Company, Pfizer, Roche Chugai, Gerd Rüdiger Burmester Speakers bureau: AbbVie Janssen, Novartis, Eli Lilly and Company, MSD, Pfizer, Consultant of: AbbVie, Janssen, Novartis, Eli Lilly and Company, MSD, Pfizer.

DOI: 10.1136/annrheumdis-2021-eular.567

\section{\begin{tabular}{|l|l}
\hline POS1034 RESPONSE TO SEQUENTIAL LINES OF BIOLOGICAL \\
\hline
\end{tabular} THERAPY IN PSORIATIC ARTHRITIS: A SINGLE CENTRE COHORT STUDY}

A. Abdalla ${ }^{1}$, A. Rambojun ${ }^{2}$, L. C. Coates ${ }^{3}$, E. Korendowych ${ }^{1}$, N. Mchugh $^{2}$, W. Tillett ${ }^{1,2}$. ${ }^{1}$ Royal National Hospital for Rheumatic Diseases, Rheumatology Department, Bath, United Kingdom; ${ }^{2}$ University of Bath, Department of Pharmacy and Pharmacology, Bath, United Kingdom; ${ }^{3}$ University of Oxford, Nuffield Department of Orthopaedics, Rheumatology and Musculoskeletal Sciences, Oxford, United Kingdom

Background: Biologic interventions using highly specific immuno-modulatory biologic disease-modifying anti-rheumatic drugs (bDMARDs) represent a rapidly developing therapeutic approach to the treatment of Psoriatic Arthritis (PsA) However, despite high rates of response, adverse events, primary and second ary inefficacy are common, and multiple sequential lines of bDMARDs are often required. Data on drug persistence, as a surrogate for response, from national registries indicates switching has become accepted routine practice. One third of patients will fail or discontinue their first biologic with a significant proportion switching on to a 3rd biologic or higher. ${ }^{1-4}$ Due to a lack of evidence on the response to sequential therapies, individual patients may not have further lines routinely funded after three bDMARDs in the UK. While limiting lines of therapy remains a UK concern, many countries with rationed healthcare systems follow the UK model of drug usage.

Objectives: To describe the response to sequential lines of bDMARD therapy prescribed in routine care in a UK single centre cohort.

Methods: A retrospective sample of patients with PsA who fulfilled CASPAR criteria and had received at least one bDMARD were taken from the Bath longitudinal cohort for inclusion in the study. Clinical and laboratory variables that constitute physician and patient-reported outcome measures were collected at baseline and after a median (range) follow-up of 3 months (2-5) into their respective therapy line in accordance with the National Institute for Health and Care Excellence (NICE) rules. The mean change with a $95 \%$ confidence interval $(\mathrm{CI})$ was used to report the difference between the baseline and follow-up measures. All patients provided consent to use their data collected during routine care, and ethical approval by the local committee was granted.

Results: The patients mean age was 57.7 (SD 12.2) with a median (range) disease duration of 14.4 years $(9.7-23.2)$. Data was available for 194 patients commencing 1st line bDMARD, 106 (2nd line), 93 (3rd line), 33 (4th line), 12 (5th line), and 9 (6th line and higher) from a total of 759 patients in the cohort. Mean tender and swollen joint count at baseline 1st bDMARD was 7 (SD 4.7) and 22 (SD 14.0), pain visual analogue scale 50 (SD 27.6) and PASI 1.3 (SD 2.2). Reasons for changing biological therapies include lack or loss of efficacy, intolerance, side effects, and comorbidities. Mean levels of joint disease at drug initiation did not diminish with subsequent lines of therapy. Clinical and patient 